\title{
An Adoption of Digital Technologies in the Supply Chain: A Review and Framework
}

\author{
Dnyaneshwar Jivanrao Ghode ${ }^{1}$, Gulab H. Dahole ${ }^{2}$ \\ ${ }^{1}$ Mechanical Engineering Department, Malaviya National Institute of Technology Jaipur, India \\ ${ }^{2}$ Mechanical Engineering Department, Government Polytechnic Gondia, India
}

Received on: 11 December, 2020, Revised on: 10 January, 2021, Published on: 16 January, 2021

\begin{abstract}
In the era of globalization, there is need to enhance the supply chain (SC) performance through transparency in transactions, security of SC system, improving the information sharing, and tracing of product. An uncertainty in the SC performance occurs due to the asymmetric information flow in the SC system. An information gap between the stakeholders of the SC can be reduced using digital technologies. Digitalization of the SC has an ability to improve the information sharing among the SC parties, provide secured system, and enhance the overall performance. Hence, this work focuses on the review of digitalization of the SC. Features of the digitalization have been presented. Challenges in the process of adoption of digital technologies in the SC have been identified. The framework for the adoption of the digital technologies in the SC has been offered to the researchers and practitioners. Finally, the implications of the digitalization have been discussed.
\end{abstract}

Keywords- supply chain, digital technology, literature review, challenges, framework.

\section{I- INTRODUCTION}

$\mathbf{S}_{\mathrm{c}}$ is the network between manufacturer and its suppliers that imparts the dispense of the manufactured products to the consumers. In the current SC structures, manufacturing of and supply of products to the customers is being done independently by the various organizations. The SC sector suffers with the many problems like delay in the delivery of the products, and fraud in the quality of the products [1]. Due to the faulty products and delayed delivery, manufacturing company may lose the orders, and hence leads to reduce the market share [2]. Sharing of information of product throughout SC is the key to improve the SC performance. The way of sharing of information is drastically changed by the use of digital instruments like mobiles, computers, automated vehicles, and drones. Digitalization has brought drastic changes in the life of human being as well as way of business [3].

SC is facing radical changes due the evolution of digitalization [4]. With the digitalization of SC, it may be possible to get at a glance information about the consignment dispatched from manufacturer to consumer [3]. To incorporate the digitalization in the traditional SC system, there is need to have an agreement between all the stakeholders of SC. Digitalization of SC helps to improve the competency of the company in the market. Digital SC includes many novel technologies like Internet of Thing (IoT), Big Data, Cloud Computing, Robots, 3D printing, Sensors, etc. [4]. Adoption of digitalization in SC results into many benefits like transparency in transactions, tracking of product, enhanced coordination of the SC members, and improved communication.

As the most of the organization are used to the traditional SC, it is very difficult them to adopt digitalization of their SC. This paper addressed the various challenges faced by the organizations to adopt digitalization into their current SC. In this paper review 


\section{International Journal of Innovations in Engineering and Science, www.ijies.net}

has been conducted; based on that various challenges have been identified. Framework for the adoption of digitization in the traditional SC has been presented. The managerial implications have been reflected. This paper provides the direction for the future research to the researchers and practitioners.

The rest of the paper is ordered as follows: Section 2 covers literature review. Section 3 discusses challenges in the adoption of digitalization in SC. Section 4 presents a framework for the adoption of digital technologies in SC. Section 5 provides the implications of digitalization of SC. Section 6 presents the discussion. Section 7 concludes this article with future research scope.

\section{II-LITERATURE REVIEW}

\section{A. Digital $S C$}

In today's global competition of businesses, there is need to use digital technologies to enhance the communication. SC is a network of manufacturing and supply of goods to the consumers. Traditional SC has a capacity to supply required products to the consumers. However, there are certain issues in the traditional SC regarding the information flow due to discrete nature of SC partners. Digitization brings all the SC partners on the same platform and enhance the information flow in the SC network [3]. Most of the population is having knowledge about the use of the digital technologies. Hence, in the competitive business scenario, it is necessary for organization to use the novel digital technologies in their SC. Adoption of digital technologies helps to transform traditional SC into digital SC.

Farahani et al., has done case studies in automotive industries to provide benchmark for the digitization of SC [5]. Cost effective SC can be developed by the integration of digital technologies with SC [6]. Scuotto et al. studied the relationship between the buyers and suppliers has been improved using the digitization of SC [7]. In the digital SC, MCDM technique can be used for the selection of proper supplier [8]. Also, Kumar et al., has done case study on manufacturing system that shows the role of digitization in smart city that changes the traditional SC [9]. Digital SC can be developed by proper guidance to the researchers and practitioners [10]. Bhargava et al. identifies challenges and provide approach for developing coordination among the stakeholders of digital SC [11].

\section{B. Features of Digital SC}

The system that combines the traditional SC system with the software and hardware to enhance the communication among the various discrete organization of SC [11]. Digital technologies make the SC system more reachable, informative, and inexpensive. Digitization of SC blends the physical flow of manufactured product with real time information flow that helps the organization to fulfill the expectation of consumers [12]. Thus, Digital SC is a system that helps to satisfy customers by providing the more accurate information about the products. Moreover, actual demand data can be transferred from consumers to the manufacturer that minimize the risk of manufacturer and improve the performance [13]. Digitization makes the SC fully automated by integration of digital technologies with traditional SC and makes it free of paper work. Digital SC provides smart platform to all the stakeholders of the SC to enhance their capabilities [14]. Many organizations think that the competition between them is mostly depend upon the SC network. Hence, every industry is trying to innovate the process of SC and bring the novelty to sustain in the competitive market. Thus, digital technology helps to evolve the traditional SC to make it more efficient and flexible. Digitalizations evolve the exiting traditional SC due its different features. These features are as follows [11]:

- Speed: Digital SC improves the speed of fulfillment of customers' demand.

- Flexibility: Due change in the market demand of products, manufacturer needs to change the production strategy. To adopt such uncertain situation, digitization helps to provide quick information of market to the manufacturer and bring the flexibility in the production.

- Communication: Digital technology bring many organizations of the SC very close and improve the communication.

- Transparency: When the transaction happens between the members of the SC, the transaction data make available to all the members due to digital technologies.

- Real-time status of stock: Manufacturer can see the real time stock of the products at the various stakeholders in the SC that helps to reduce the Bullwhip effect. 


\section{International Journal of Innovations in Engineering and Science, www.ijies.net}

- Intelligent: Digitization sense the demand of the customers and allow SC to take smart decision to bring novel products in the market.

- Less Cost: Initial cost of the digitalization may be high, but with time the cost gets recover quickly to provide.

- Scalability: Digital SC reduces the paper work. More data can be stored securely in the small place by using digital technologies.

- Innovative: Novelty in any product always attracts the customers. Digitalization in SC helps to find the trend of the market about particular product and make innovation in the existing product to provide it to the customers with faster rate.

- Proactive: In case of any disruption, digital SC proactively adopt itself as per the situation and offers troubleshooting to the problems.

\section{III-CHALLENGES OF DIGITAL SC}

SC is a complex network of flow of product from manufacturer to the consumer in which many problems may arise. In digitalization of SC, many stakeholders of the SC should come on the same platform, share their data and manage the activities in coordination with all the other members of SC. Development of common software platform for all the SC stakeholders is the main challenge. Likewise, management of database, product flow, supply and demand data, quality of products, and logistics management are some challenges before the adoption of digital technology in SC. From the literature review challenges have been identified as shown in Table I.

Table I -CHALLENGES IN DIGITILIZATION OF SC

\begin{tabular}{|l|l|c|}
\hline Challenges & Description & $\begin{array}{l}\text { Literature } \\
\text { Source }\end{array}$ \\
\hline $\begin{array}{l}\text { Inter } \\
\text { organizational } \\
\text { coordination }\end{array}$ & $\begin{array}{l}\text { Lack of coordination } \\
\text { among the various } \\
\text { organizations in the SC } \\
\text { about the use of digital } \\
\text { technologies. }\end{array}$ & {$[15]$} \\
\hline $\begin{array}{l}\text { Sharing of } \\
\text { Information }\end{array}$ & $\begin{array}{l}\text { Many organizations are } \\
\text { hesitant to the sharing of } \\
\text { information. }\end{array}$ & {$[16]$} \\
\hline $\begin{array}{l}\text { Integrity of } \\
\text { data }\end{array}$ & $\begin{array}{l}\text { Uncertainty about the } \\
\text { correctness and source of } \\
\text { data. }\end{array}$ & {$[17]$} \\
\hline $\begin{array}{l}\text { Assurance of } \\
\text { success }\end{array}$ & $\begin{array}{l}\text { Overconfidence in the } \\
\text { digital technology may } \\
\text { lead to errors in the }\end{array}$ & {$[18]$} \\
\hline
\end{tabular}

\begin{tabular}{|l|l|c|}
\hline & output. & \\
\hline Instability & $\begin{array}{l}\text { Volatile market } \\
\text { conditions affect the } \\
\text { adoption of digital } \\
\text { technologies in the SC }\end{array}$ & \\
\hline Training & $\begin{array}{l}\text { People working in the } \\
\text { SC are deficient with } \\
\text { knowledge of new } \\
\text { technology [18] }\end{array}$ & \\
\hline $\begin{array}{l}\text { Vision of } \\
\text { integration }\end{array}$ & $\begin{array}{l}\text { Different views of the } \\
\text { various stakeholders of } \\
\text { the SC on the integration } \\
\text { with digital technologies. }\end{array}$ & \\
\hline
\end{tabular}

For the adoption of digital technologies in the SC, there are seven challenges identified from the literature review. For the adoption of digital technologies in the $\mathrm{SC}$, the identified challenges should be overcome. As there are various organizations involved in the SC and every organization has different rules and regulations about the adoption of new technology, the coordination problem between them arise [15]. Many organizations do not want to share their data with other organizations in the SC [16]. Moreover, many companies taken granted the improvement in the performance of the SC due to digitalization [18]. Also, before the adoption of the digital technologies in the SC needs the short-term and long-term planning of the business. For that, proper train manpower should be available to handle the changes in the existing traditional SC system [18]. In this view, proper planning is needed to overcome the identified challenges for the adoption of digital technologies in the traditional SC. The proper implementation of digital technologies in the SC leads to the enhancement of the performance of the SC.

\section{IV- FRAMEWORK FOR DIGITAL SC}

Success of SC mainly depends on the framework for adoption of digital technology in SC. It is required to develop a structure that provides the pathway of adoption of digital technologies in the SC. From the extant literature, various characteristics, challenges, and advantages have been identified to build the framework for the adoption of digital technology in the SC. Fig. 1 shows the framework for the adoption of digital technology in the SC. In the framework, SC objectives to be set first. Mainly the SC objectives are to improve communication among the stakeholders of the SC, to enhance the coordination in the SC network, to improve the overall performance of the SC, and to minimize the risk in the difficult situations like pandemic, natural 


\section{International Journal of Innovations in Engineering and Science, www.ijies.net}

disaster etc. To achieve these objectives, use cases of the digitization should be studied through literature review, and find the features of the digital technologies. Challenges to adopt the digital technologies like achievement of scalability, adoption of innovations, trainings required for digitization, instability in the SC, and the maintaining data integrity. After identification of the challenges, the solution should be found out and overcome these challenges to achieve the advantage of the digitization of $\mathrm{SC}$ in the competitive market. Digitized SC able to achieve the transparency in the transactions between the SC members, security of the SC network, improve the trust among the organizations of the SC network, and helps to minimize the SC risk.

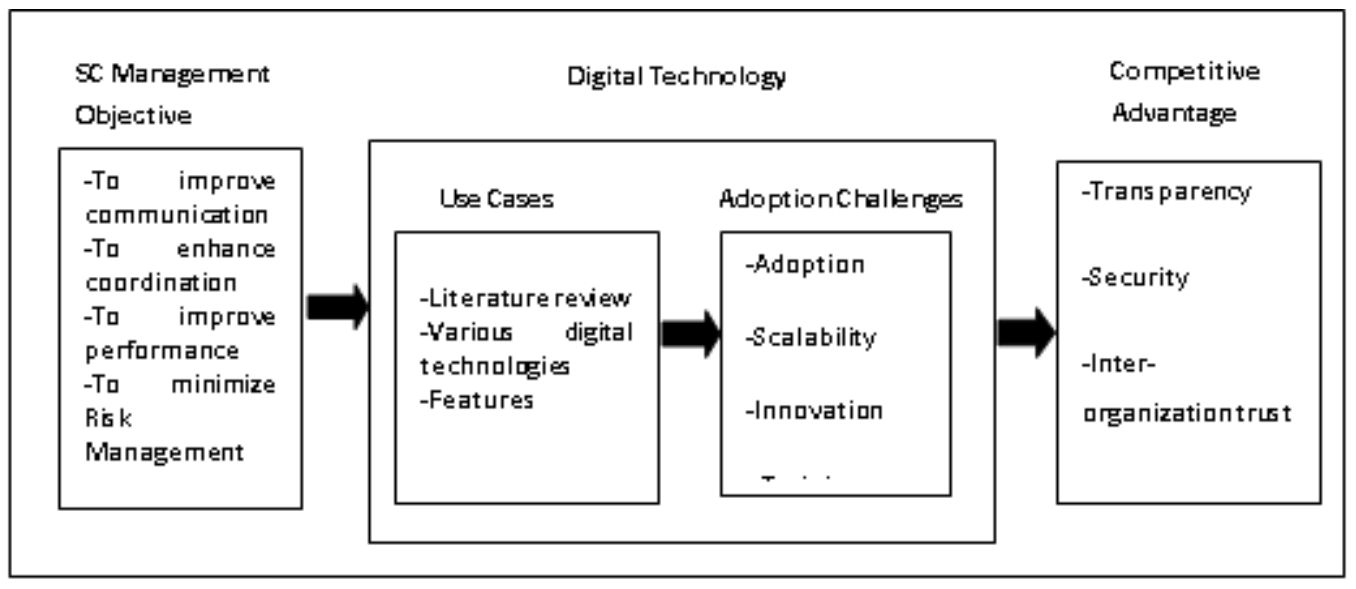

Fig.1: Framewark of Adaptian of Digit al Technalagy withSC

Framework of digitization of SC will be helpful to the SC managers to get the basic way of adoption of the digital technologies in the SC. It shows the step by step implementation of digital technologies in the SC. Accessing the current status of the SC and the identifying the hurdles in the implementation helps the researchers and practitioners. Then, the digitalization of $\mathrm{SC}$ can be done to improve the overall performance of the $\mathrm{SC}$.

\section{V-IMPLICATIONS}

In the era of industry 4.0, digitization will reform the SC. It will help to give the financial benefits to the businesses [19]. Many industries have their established $\mathrm{SC}$ and they do not want to make any changes in the existing SC system. Moreover, there are many financial limitations for many companies. In this view, most of the companies hesitate to implement such budding technology in their existing traditional SC [3]. In the global competitive market, businesses are looking to improve their market share. Hence, the new digital technology may help them to provide transparency in their product information to the customers. That helps to enhance the trust of the customer and improve faith in the product brand. In this way, digitization of the SC can be utilized in the branding of the products.

Adoption of digital technologies evolves the managerial way of thinking, revolutionaries the business models, and brings innovations. Digital technologies offer flexibility and effectiveness in SC from the point of view of the consumers. The strategy for managers is to execute the stepwise implementation of the digitization of the SC that should focus on the output provided to the customers. To achieve the objective of adoption of digital technologies in the SC, the key task is to develop framework that offers a stepwise plan for management of digitization of SC. Hence, the adoption digital technology in the SC transforms the traditional SC and offers an improvement in the performance of the organizations. Innovative concepts convey new ideas to the managers for the requisite solutions to the problems in the complex business environment.

This paper provides an insight into the literature review to identify the various challenges, and offer a framework that will help the researchers and practitioners for the digitalization of the SC to achieve the benefits of transparency of transactions to the stakeholders of the SC, secured SC system that cannot be tampered, scalability that can stored big data, and overall 


\section{International Journal of Innovations in Engineering and Science, www.ijies.net}

improvement in the performance of the SC. In this way, this paper provides a strong guideline to the researchers and practitioners to adopt digital technologies in the SC. For the survival in the global competitive market, organizations should adopt the digitalization in their SC. The presented framework is generic and can be modified while implementation in the specific SC system.

\section{VI -DISCUSSION}

In the current timeframe, every aspect of human life is touched with digitalization. So, it is the need to transform SC using digital technologies. Managers of SC have focused to present their products to the consumers in a transparent way to earn the faith of the customers. Digitalization has a critical role in this process. Many, technologies like IoT, Cloud Computing, Big Data etc. can be used to change the current form of the SC into digital form. This helps to provide flexibility, and transparency in the SC system due to symmetric information flow.

This study provides an inclusive method to adopt the digital technology in the SC. Consequently, a stone step is provided to researchers and practitioners to do the digitalization of SC. The potential needed to adopt the digital technology in the SC can be achieved through proper trainings that enrich the employees with the required skills. Foremost task is to bring all the stakeholders of the SC on one platform for digitalization, as many organizations have different business strategies. Several organizations do not want to share their transaction data with other organizations. There is need to maintain the balance between the transparency and confidentiality of the data of the various organization in the SC. Digitalization of SC does not assure the improvement in the performance. The complete reliance on the digital technology may be harmful sometimes. With digitalization, skillful manpower should be there to handle the challenges in the execution. Unstable market condition has an impact on the adoption of the digital technologies in the SC. in such condition, choice of proper digital technology plays a crucial role. In all, managers of the company should have vision about the necessity of the digitalization and the execution plan.

The challenges mentioned in the adoption of the digital technologies in the SC should be overcome and execute the implementation plan of digital technologies in the SC. It benefits the SC in the respect of improvement in the information flow due to transparency in transactions.
Products can be traced by the consumers leads to improve in belief in the process of manufacturing of the product and ultimately on the product brand. In case of risky situation, digitalization helps to provide the flexibility in the SC of the product using digitized data about the suppliers, distributors, and retailers at various geographical locations. This will help to minimize the risk of the SC system. In this way, digitalization helps to enhance the overall performance of the SC and sustain in the global competitive market.

\section{VII-CONCLUSION AND FUTURE RESEARCH DIRECTIONS}

The main focus of this study is the literature review and to develop framework for the adoption of the digital technologies in the SC. The guidelines for the digitalization of the SC presented in this work will be helpful to the researchers and the practitioners. In this work, literature review has been done to identify the challenges in the adoption of digital technologies in the SC. The challenges are: inter organizational coordination, sharing of information, integrity of data, assurance of success, instability, training, and vision of integration. Consequently, framework to provide plans for the digitalization of SC has been presented. In the framework, firstly the SC objectives have to be defined that have to be achieved after digitalization, then the literature review has to be done to identify the various barriers in the digitalization process, and at the end the improvement in the SC performance can be achieved after the overcoming the challenges and implementation of the digital technology in the SC.

In addition, the implications in the researcher and manager point of view have been discussed. This will help the practitioners for the execution of digitalization in the SC. The work presented here tries to provide insight the adoption process of digital technologies in the SC.

In future, the actual case study for the digitalization of SC can be done and based on that the framework can be presented. The specific digital technology like IoT, cloud computing etc. can be implemented in the real time SC of any product and evaluation of performance of that SC system can be done. 


\section{International Journal of Innovations in Engineering and Science, www.ijies.net}

\section{REFERENCES}

[1] R. Casado-Vara, J. Prieto, La Prieta, F. De, and J. M. Corchado, "How blockchain improves the supply chain: Case study alimentary supply chain," Procedia Computer Science, vol. 134, pp. 393-398, 2018. https://doi.org/10.1016/j.procs.2018.07.193

[2] Y. Zhao, T. M. Choi, T. C. E. Cheng, and S. Wang, "Supply option contracts with spot market and demand information updating," European Journal of Operational Research, vol. 266(3), pp. 1062-1071, 2018. https://doi.org/10.1016/j.ejor.2017.11.001

[3] G. Büyüközkan, and F. Göçer, "Digital Supply Chain: Literature review and a proposed framework for future research," Computers in Industry, vol. 97, pp. 157177 ,

2018.

https://doi.org/10.1016/j.compind.2018.02.010

[4] S. Fosso Wamba, and M. M. Queiroz, "Industry 4.0 and the Supply Chain Digitalization: A Blockchain Diffusion Perspective," Production Planning \& Control, vol. O(Forthcoming), pp. 1-18, 2020. https://doi.org/10.1080/09537287.2020.1810756

[5] P. Farahani, C. Meier, and J. Wilke, "Digital supply chain management agenda for the automotive supplier industry," Shap. Digit. Enterp., Springer International Publishing, Cham, 2017, pp. 157-17210.1007/978-3319-40967-2_8.

[6] K. Korpela, J. Hallikas, and T. Dahlberg, "Digital supply chain transformation toward blockchain integration," Proc. 50th Hawaii Int. Conf. Syst. Sci., 2017, $\quad$ pp. 4182-4191. http://hdl.handle.net/10125/41666.

[7] V. Scuotto, F. Caputo, M. Villasalero, and M. Del Giudice, "A multiple buyer- supplier relationship in the context of SMEs' digital supply chain management," Production Planning and Control, vol. 28, pp. 1378-1388, 2017. doi:http://dx.doi. org/10.1080/09537287.2017.1375149.

[8] G. Buyukozkan, and F. Gocer, "An extention of ARAS methodology based on interval valued intuitionistic fuzzy group decision making for digital supply chain," 2017 IEEE Int. Conf. Fuzzy Syst., IEEE (2017), pp. 16, doi:http://dx.doi.org/ 10.1109/FUZZIEEE.2017.8015680.

[9] M. Kumar, G. Graham, P. Hennelly, and J. Srai, "How will smart city production systems transform supply chain design: a product-level investigation," International Jouranl of Production Research, vo. 54 (2016), pp. 7181-7192, 2016. doi:http://dx.doi.org/10.1080/00207543.2016.1198057.

[10] L. Wu, X. Yue, A. Jin, and D.C. Yen, "Smart supply chain management: a review and implications for future research," International Journal of Logistics Management, vol. 27 (2016), pp. 395-417, 2016. doi: http://dx.doi.org/10.1108/IJLM-02-2014-0035.
[11] B. Bhargava, R. Ranchal, and L. BenOthmane, "Secure information sharing in digital supply chains," 2013 3rd IEEE Int. Adv. Comput. Conf. (2013) pp. 1636-1640, doi: http://dx.doi.org/10.1109/IAdCC.2013.6514473.

[12] S. Raj, and A. Sharma, "Supply Chain Management in the Cloud," (2014) . https:// www.accenture.com/tren/insight-supply-chain-management-cloud (Accessed on 18 August 2020)

[13] "The Digital Supply Chain Initiative, Digital Supply Chains: A Frontsite Flip, Sanya, China, 2015”. https://www.cadenadesuministro.es/wpcontent/uploads/2016/10/Digital-Supply-Chains-AFrontside-Flip.pdf (Accessed on 15 July 2020)

[14] M. Rouse, "Digital Supply Chain, Search Manufacturing ERP.com," (2016) 30 March, http://searchmanufacturingerp.techtarget.com/definitio n/digital- supply-chain?vgnextfmt=print. (Accessed 11 July 2020)

[15] S. Schrauf, and P. Berttram, "Industry 4.0: How Digitization Makes the Supply Chain More Efficient, Agile, and Customer-focused, Strategy," (2016) . http:// www.strategyand.pwc.com/reports/industry4.0. (Accessed on 20 June 2020)

[16] J. Xu, "Managing Digital Enterprise," Atlantis Press, Paris, 2014, doi:http://dx. doi.org/10.2991/978-946239-094-2.

[17] R.G. Richey, T.R. Morgan, K. Lindsey-Hall, and F.G. Adams, "A global exploration of big data in the supply chain," International Journal of Physical Distribution and Logistic Management, vol. 46, 2016. doi: http://dx.doi.org/10.1108/IJPDLM-05-2016-0134

[18] T. Hines, "Supply chain strategies: customer-driven and customer-focused," (2004) .

[19] S.F. DeAngelis, "Digital enterprises rely on digital supply chains," Enterra Solut. (August) (2015) http://www.enterrasolutions.com/2015/08/digitalenterprises-rely-on-digital-supply-chains.html. (Accessed 15 August 2020). 